\title{
Automatic control of the sand granulation process to improve homogeneity in the manufacture of ceramic tiles
}

\author{
Guillermo Morales-Romero ${ }^{1}$, Adrián Quispe-Andía², Beatriz Caycho-Salas ${ }^{3}$, Nicéforo Trinidad-Loli ${ }^{4}$, \\ Cesar León-Velarde ${ }^{5}$, Carlos Palacios-Huaraca ${ }^{6}$, Omar Chamorro-Atalaya $^{7}$ \\ 1,2,3,4 National University of Education Enrique Guzmán y Valle, Lima, Perú \\ ${ }^{5}$ University Tecnólogica del Perú, Lima, Perú \\ ${ }^{6}$ University Cesar Vallejo, Lima, Perú \\ ${ }^{7}$ Faculty of Engineering and Management, National Technological University of Lima Sur, Lima, Perú
}

\begin{tabular}{|c|c|}
\hline Article Info & ABSTRACT \\
\hline Article history: & The purpose of this article is to quantify to what extent the design of an \\
\hline Received Apr 1, 2021 & $\begin{array}{l}\text { automatic control system for the clay sand granulation process will improve } \\
\text { the percentage of homogeneity in the manufacture of ceramic tiles, through }\end{array}$ \\
\hline Revised Sep 8, 2021 & the analysis of the percentage of dust moisture. For which the process under \\
\hline Accepted Sep 17, 2021 & $\begin{array}{l}\text { study is initially described, identifying its stages, the control strategy to be } \\
\text { used and its main characteristics. After conducting the research, it was }\end{array}$ \\
\hline Keywords: & $\begin{array}{l}\text { determined that from the proposed control strategy, in which the flow of clay } \\
\text { sand is controlled through frequency variators and the sequential injection of }\end{array}$ \\
\hline Ceramic tiles & water spray through electric nozzles, it was achieved improve the \\
\hline Control system & $\begin{array}{l}\text { homogeneity percentage by } 94.78 \% \text {, achieving that the error between the } \\
\text { desired value and the present value of the humidity percentage is } 0.015 \% \text {, the }\end{array}$ \\
\hline Granulated powder & approximation to the desired value or setpoint value being significant. Thus, \\
\hline Granulation process & it was also possible to determine that through an analysis of the dispersion \\
\hline Homogeneity & model, that the collected data respond to a constant; evidencing that there is \\
\hline Quality & $\begin{array}{l}\text { no sudden variation in the percentage of homogeneity during the automated } \\
\text { operation of the process, which validates the improvement of homogeneity in } \\
\text { the manufacture of ceramic tiles. }\end{array}$ \\
\hline
\end{tabular}

This is an open access article under the CC BY-SA license.

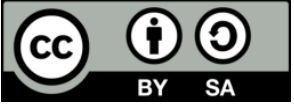

Corresponding Author:

Guillermo Morales-Romero

National University of Education Enrique Guzmán y Valle

Comas, Lima- Peru

Email: gmorales@une.edu.pe

\section{INTRODUCTION}

Currently, companies constitute a support for competitiveness in the productive sector [1], [2], companies seek to achieve competitiveness based on the use of various technologies, in order to control the myriad of variables that determine the optimal operation of the industrial process and that guarantee quality production of the manufactured product [3]. Moreover, it is that in the current context in which we find ourselves, which is characterized by globalization and a highly competitive environment for companies, they seek to achieve and show a solid operational performance [4]-[6]. Becoming tools such as automatic process control, and fundamental means for the redesign of the evolution of industrial processes [7]-[10]. In this competitive context, demarcated by incessant innovative technical change, it is imperative to modify and reorient the philosophy of drive and operation of the components of a plant or production process [11]-[13]. Today, when talking about competitiveness and comparative advantages in industrial sectors, it is necessary to inquire about the potential of a country in relation to the technological component of innovation [14]-[16]; competitiveness in industrial sectors is also associated with the possibility of inserting and developing 
technologies such as automatic process control in industry [17]-[19]. For this reason, decision-making and the execution of actions to govern a production process goes through the use of an automatic control system [20]; the automatic system is the one who takes into account the measurement and analysis of the variables, to guarantee an efficient development of the industrial process [21].

Thus, in the current manufacturing industry, whose processes are continuous processes require machines and production plants commonly controlled by programmable algorithms [22], being the programmable algorithms those that offer the capacity of scalability and rapid adaptation to new requirements of the production process [23]. Now, if we focus on the ceramic production industry, in the last thirty years there has not been an authentic transformation of the ceramic tile production process [24]; in the production of ceramic materials, there is a large percentage of companies that have been presenting problems in their manufacturing processes, related to production time, the quantity of production and the quantity of raw material lost due to poor quality or operation [25]. Therefore, not all ceramic tile-manufacturing processes can be considered a technologically mature process [26], from the technological point of view, most manufacturing processes lack tools that guarantee a productive process with quality [27]. In order to solve the problem of the companies generated during the production process, technologies that allow the automation and control of processes must be integrated, thus guaranteeing the improvement of the quality of the final product and the increase in productivity [28]. There are three factors that predominate over the quality of ceramic tiles, one is the equipment used, human resources and raw materials [29], According to various antecedents, automatic systems are capable of controlling the various aspects that intervene in the manufacturing process of ceramic materials, thereby influencing the improvement of the factors described [30].

Likewise, in ceramic product manufacturing companies, there are different factors related to the quality of the production process and raw materials such as humidity, the dosage of clays and pigments, affect the appearance of the final product [31]. It turns out, then, that it is necessary to develop new technologies that allow improving and ensuring the quality of ceramic tiles, in order to guarantee the homogeneity of the components to obtain the final product and avoid waste of inputs [32], even more being known that many companies dedicated to the production of ceramic pieces generate a large amount of waste daily due to production defects [33]. In addition, the thing is that there are many companies worldwide, but in underdeveloped countries in the ceramic tile sector, that do not make use of automatic control technology and industrial automation [34]. In this regard, it is pointed out that in Peru, to cite one case, there are few companies dedicated to the production process of ceramic tiles that have technological tools that allow them to ensure the quality of their products [35]. Thus, the companies dedicated to the production of ceramic tiles have a great challenge, which is focused on using automated systems based on process control strategies [36], the purpose of incorporating control technology is to achieve optimally dose the inputs used in order to avoid production reduction and improve the quality of the final product [37].

In this context, the main problem addressed in this investigation is that currently, even when technological progress is evident and noticeable, many companies dedicated to the manufacture of ceramic tiles have their processes operating manually, without precision, without monitoring, without self-regulating control capacity; which generates irreparable losses from the point of view of productivity, since when the desired homogeneity is not achieved in the process of mixing the sand granulate, all the inputs used are wasted, not being able to be used again, and generating lost man-hours and hours machine. As indicated in the previous paragraphs, this article aims to determine to what extent the design of an automatic control system for the clay sand granulation process improves the percentage of homogeneity in the manufacture of ceramic tiles. For which initially the control strategy and its characteristics will be described; then the quantitative results of the measurements of the indicator under study (percentage of dust moisture) will be shown, which are directly related to the quality of the homogeneity of ceramics, achieved with the implementation of the automatic control system. Thus, a statistical analysis of the distribution of the collected data will also be used in order to establish the dispersion model that will help to determine if the automated system allows achieving self-regulation of the moisture percentage of the granulated powder, once the system is automated.

\section{RESEARCH METHOD}

\subsection{Design and research level}

The research design carried out in this article is experimental, because it seeks to generate an effect of the indicator, percentage of humidity of the granulated powder, which is directly related to the quality of the homogeneity of ceramics. The research level is descriptive, since the average values of the humidity percentage obtained during a period of the work cycle will be analyzed, in order to determine the impact of improvement obtained from the implementation of the automated system from these values. 


\subsection{Data collection}

Data collection was obtained from the application of a registration form, which represents the data measurement instrument; regarding the data collection techniques to be applied, these were observation (because an instrument called a high-precision granulometer was used) and documentary analysis, because information from the records of the percentage of moisture in the dust was used, granulate before the automation of the industrial process. The method used for data collection was the same before and after the self-validation of the process; In other words, because the work cycle of the granulated process is carried out for a period related to the capacity of clay sand in the hopper, it is so that in one day a total of 40 samples were obtained; each sample captured every 15 minute period. In such a way that the scheme of the data collection method will be represented by Table 1 .

Where MOi represents the data observed in period $\mathrm{i}$, during the manual process and MAi represents the data observed in period i, during the automated process. Likewise, XMO represents the average of the observations of the controlled variable before the automated process and YMO represents the average of the observations of the variable after the application of the control strategy. Finally, $\Delta \mathrm{X}$, will represent the impact of improving the percentage of humidity of the granulated powder.

Table 1. Outline of the data collection design

\begin{tabular}{|c|c|c|c|c|}
\hline$T_{i}$ & $\mathrm{~T}_{1}$ & $T_{2}$ & \multicolumn{2}{|l|}{$\mathrm{T}_{40}$} \\
\hline $\mathrm{MO}_{\mathrm{i}}$ & $\mathrm{MO}_{1}$ & $\mathrm{MO}_{2}$ & $\mathrm{MO}_{40}$ & $\mathrm{XMO}$ \\
\hline MAi & $\mathrm{MA}_{1}$ & $\mathrm{MA}_{2} \quad \mathrm{MA}_{3}$ & $\mathrm{MA}_{40}$ & YMO \\
\hline & \multicolumn{2}{|r|}{$\Delta \mathrm{X}$} & \multicolumn{2}{|c|}{ YMO - XMO } \\
\hline
\end{tabular}

\section{PROCEDURE}

\subsection{Description of the sand granulation process}

Before proceeding to describe the automated process, I will firstly need to describe the stages that intervene in the clay sand granulation process to generate the wetted powder as the main component in the ceramic tile production process, in order to define the analysis, of identify where the variable and indicator addressed in this scientific article are found. The first stage begins with the verification that all the fuse holders of the silos are connected to the electrical panel, the same one that is located in the press area; in which you must select the silos to be unloaded to the press. It is important for this to take into account the stock of dust in all silos, in order to make a correct distribution in the press feed.

The amount of discharge flow must be taken into account, if it is adequate in order to avoid vacuum due to lack of powder or, failing that, excess powder, which could cause clogging of the feeding system. In the second stage, the coarse and fine granule detection test is carried out, for which samples are taken from the mill outlet; a total of $1 \mathrm{Kg}$. of the sample is taken and then sieved using mesh number 50; what remains on the mesh is called fine, and this component is subjected to a granulometry test. In the last stage is the control of the humidity percentage, this verification is carried out manually and periodically for 15 minutes, taking as a reference the duration of a work cycle of the production process, recording the values in a register.

As can be seen in Figure 1, in stage 3 the aspect that determines the level of wetting of the granulated powder is focused, in order to guarantee adequate homogeneity in obtaining ceramic tiles; as part of the control strategy and considering that the regulation of the humidity percentage can be done through the automatic control of the sand flow that enters the granulation process and through the amount of water that is inserted into the sand flow through the sequential actuation of electric nozzles; next, it is specified how to proceed to improve the process of this process in order to guarantee the values defined as optimal for the sand granulation process to generate the wetted powder. It should be noted that the control strategy that was developed considering that the desired value for the indicator under analysis (percentage of dust moisture), should not be outside the range between $6.9 \%$ and $7.1 \%$, which is why the automation described.

\subsection{Description of the automated process}

Pressing the start button automatically produces the passage of sand composed of clay from the hopper, duly processed; This hopper contains a lower level sensor, which, upon detecting the presence of clay sand, will immediately activate a timer with a delay on connection; the same one that will establish, that after five hundred seconds; that is, when the hopper reaches $75 \%$ of its storage capacity, the following elements begin to operate automatically. A broken valve at an initial operating frequency of twenty Hertz, a conveyor screw valve driven by a motor (motor 1), a motor pump that injects water into the humidification stage through nine electric nozzles at a pressure of eleven bar and a motor that will drive the axis for the 
homogenization of the wetting stage. In the aforementioned stage, a microwave humidity control probe will be used, which will be connected to the programmable logic controller, in order to establish a closed control loop, permanently comparing the desired value for humidity (7\%), with the present value; thus generating an error signal, which will be interpreted by the programmable logic controller to send a signal either to the frequency variator that will regulate the flow rate of the broken valve or to the electric nozzles that will inject sprayed water, to its on or off, as the case may be.

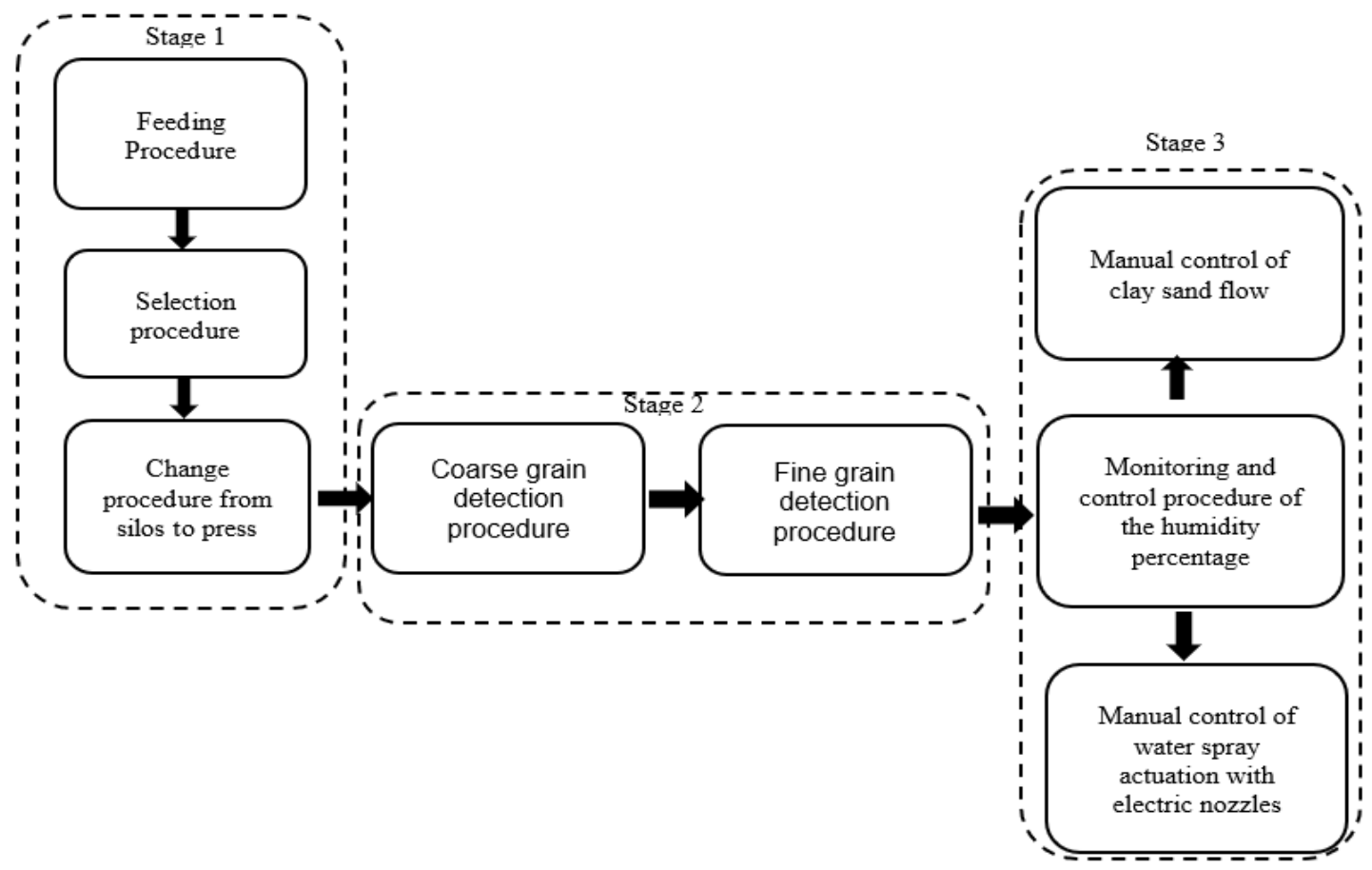

Figure 1. Stages of the granulation process

The initial operating conditions in the case of the roto valve is twenty Hertz in frequency, while in the case of the water nozzles, of the nine available only five nozzles will be open. After reaching the optimum humidity percentage for the mixture, or reaching the desirable value range, the mixture outlet solenoid valve is opened for a period of five hundred seconds; this same time the motor of the conveyor belt will also be on, which will transfer the mixture to the next stage. Figure 2 shows the elements and components described in the previous paragraphs; in which it is specified that there are two scenarios on which the automatic control system is supported; The first is when the granulated powder is very humid, in this case it must go through some heaters to dry and return to the granulator silo; While the second scenario is when the granulated powder is very dry, in this case it must return to the granulator silo so that they act on the electric nozzles that inject sprayed water, and moisten the powder.

Also, we proceed to describe the partial programming of the programmable logic controller, used to develop the control strategy. In Figure 3, it is shown in the programming that initially a start button (I1) and a stop button (I2) are used, in order to establish the activation and shutdown of the entire process, for which use was made a reset set block (B001), whose function is to activate the entire process; When the start button is pressed and due to the reset block, a signaling pilot (Q1) is activated, which indicates the filling of the hopper with clay powder, after filling, a lower level sensor is established (I3) ; which when closed, sends a signal to the logic gate And (B002), which activates the timer with delay to the connection (B004), after 500 seconds, a signal is sent, the same that will start the ignition of the working bodies. (Broken valve: Q2, Screw conveyor motor: Q3, Pump motor Q5 and Shaft motor: Q4). 


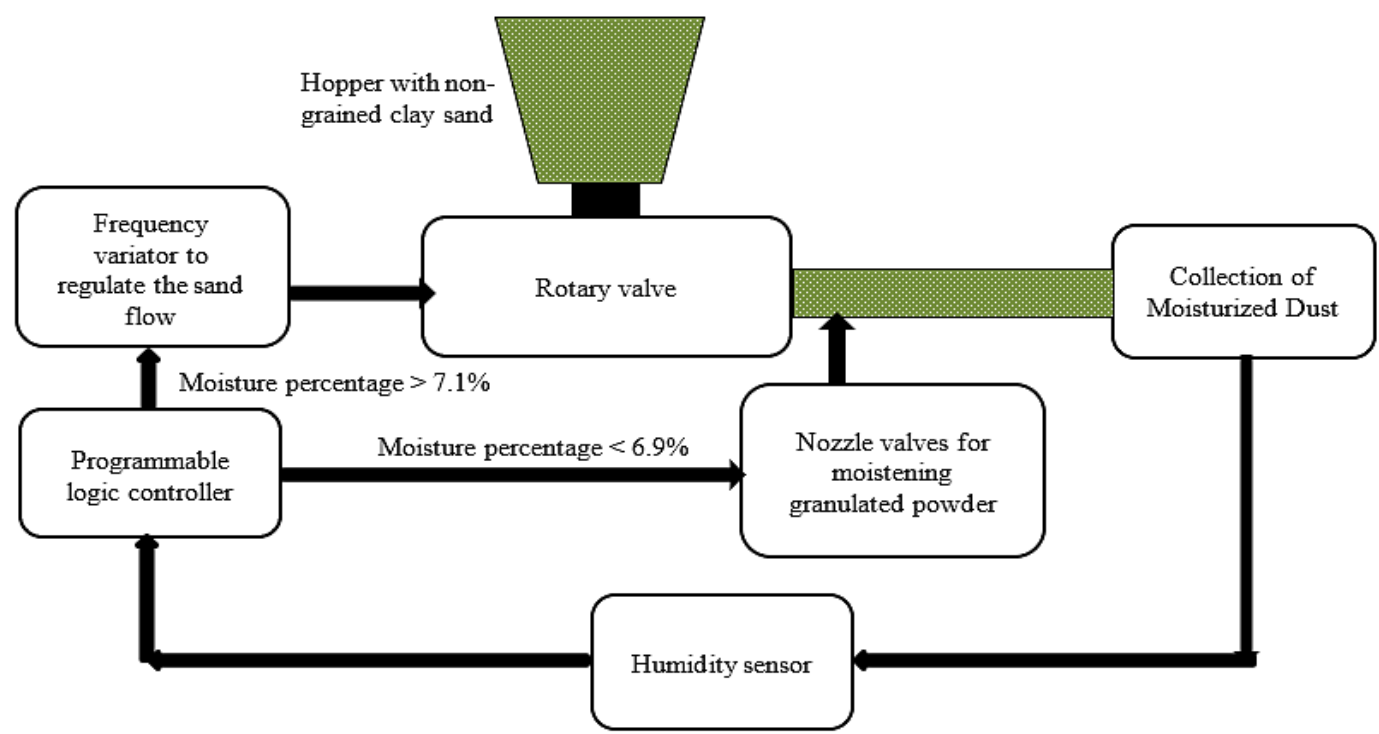

Figure 2. Control strategy for the process

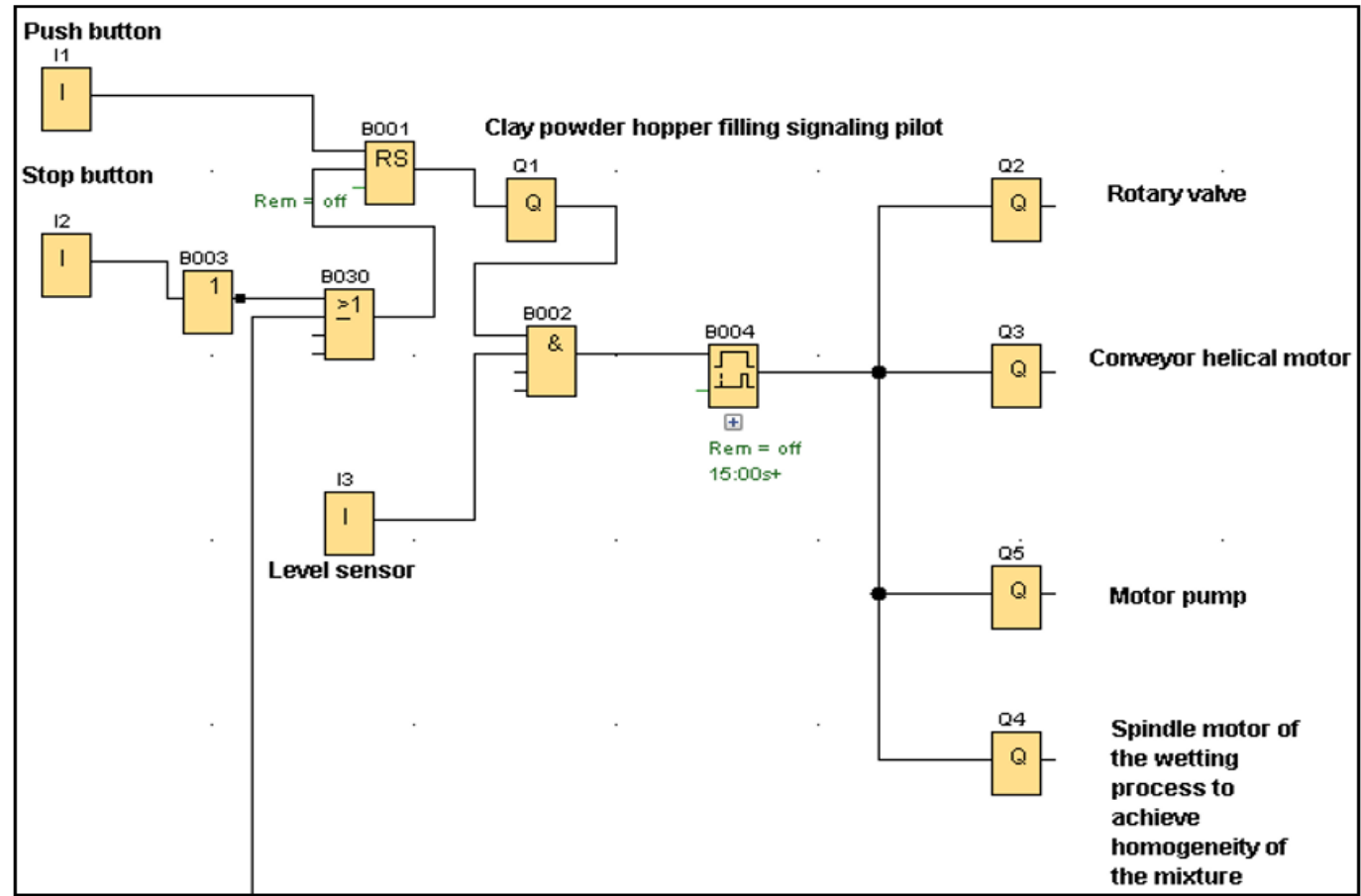

Figure 3. Programming of the start and stop stage of the sand granulation process

\section{RESULTS AND DISCUSSION}

\subsection{Results}

From the data collected, it is observed in Figure 4 that the effect of the application of the proposed control strategy to a significant result, since it has been achieved that the oscillation ranges of the percentage of humidity of the granulated powder, is self-regulated by the controller, within the desired limits. This effect is visibly perceived in Figure 5, since it is possible to compare the behavior of the controlled variable of the automated system with the oscillating behavior when the process did not respond to a control strategy, but on the contrary to a strictly manual process. While the minimum and maximum oscillation levels turn out to be $3.4 \%$ and $7.8 \%$ respectively in the manual process, generating a lack of homogeneity in the moistened powder as an element for the manufacture of wax tiles; in the automated process, the oscillation is between $6.9 \%$ and $7.1 \%$. 


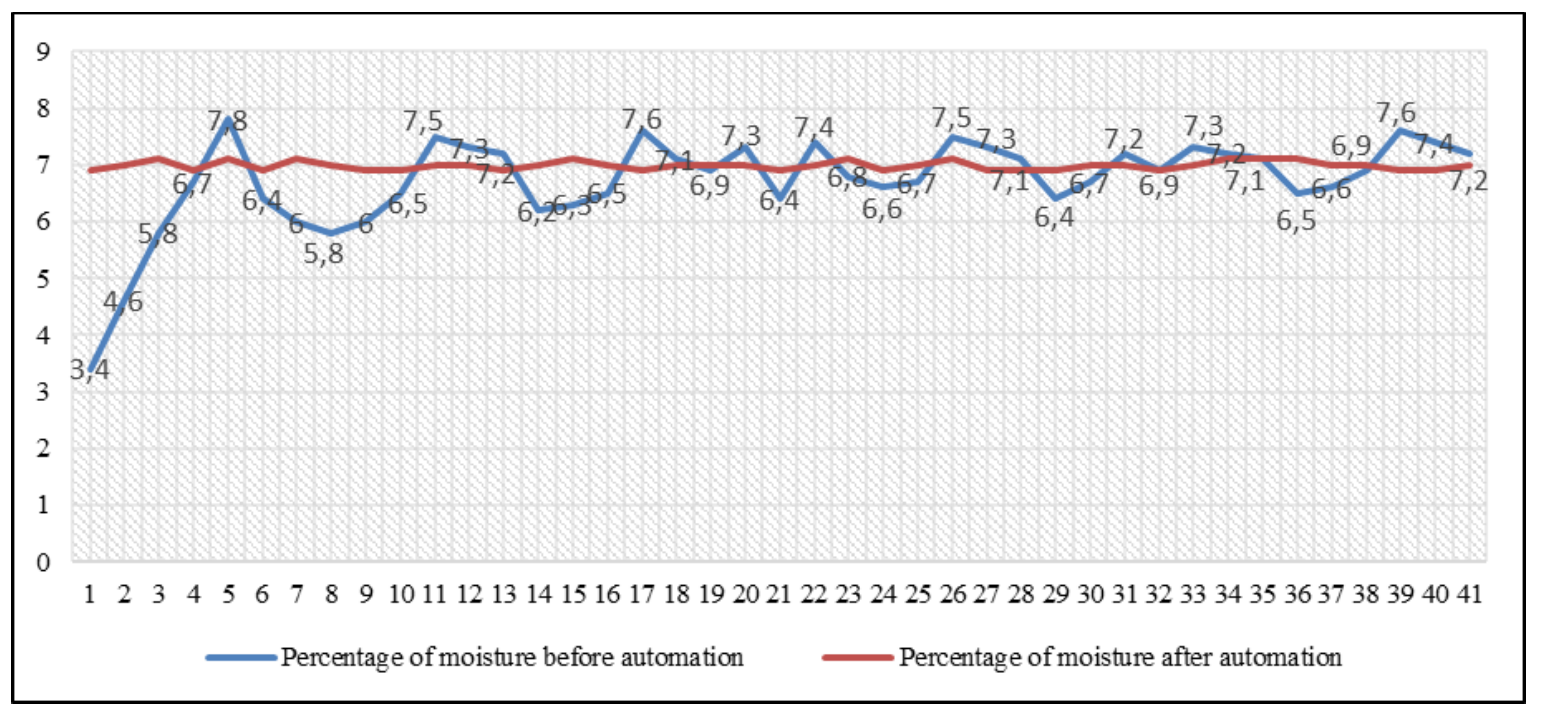

Figure 4. Comparison of the levels observed with respect to the percentage of humidity of the granulated powder $(\%)$

From the descriptive analysis of the data a shown in Table 1, with statistical indicators obtained from the statistical product and service solutions (SPSS) version 25 software; whose data will show the average improvement percentage obtained between two scenarios, the first, described by a manual process and the second described by an automated process under a control strategy. From Table 2, the impact of improvement in the process can be obtained through the comparison of averages from the control strategy described in this research, it is achieved that:

- The variation between the average value observed in the manual process and the set point or set point of the percentage of humidity of the granulate powder is 0.2875 .

- While the variation between the average value observed in the automated process and the set point or set point of the percentage of humidity of the granulate powder is 0.015 .

Table 2. Descriptive indicators of the variable under analysis

\begin{tabular}{lcccccc}
\hline & Descriptive statistics & & \\
& $\mathrm{N}$ & Rank & Minimum & Maximum & Average \\
\hline Percentage of humidity after the process automation & 40 & 0.20 & 6.90 & 7.10 & 6,9850 \\
Percentage of humidity with the manual process & 40 & 4.40 & 3.40 & 7.80 & 6,7125 \\
\hline
\end{tabular}

From this analysis, it is found that the improvement impact is $94.78 \%$, compared to what was had in the manual process. Thus, it is also possible to find through the statistical analysis of the dispersion model and curvilinear estimation, shown in Figure 5, that the variable to control, that is, the percentage of humidity, turns out to be independent of time or rather of the observed period; which allows us to specify as a finding that its behavior is constant, that is, the data collected after the application of the control strategy turned out to be statistically verified through the analysis of the curvilinear estimation model, in which it is defined that the variation is almost null, managing to check the control of the system over the humidity percentage.

In the straight line in Table 3, the coefficients that define the equation of the behavior of the variable under analysis are shown, which further reinforces the representation shown in Figure 5. It is specified that since the constant "b1" is equal to zero, makes the behavior model of the controlled variable defined only by the value of $6.983 \%$, very close to the desired value or set point whose value is equal to $7 \%$.

Table 3. Estimation of coefficients that define the equation for the behavior of the variable under analysis

\begin{tabular}{cccccccc}
\hline Equation & \multicolumn{4}{c}{ Model Summary } & \multicolumn{3}{c}{ Parameter estimates } \\
& R square & F & gl1 & gl2 & Sig. & Constant & b1 \\
\hline Lineal & 0.000 & 0.011 & 1 & 38 & 0.919 & 6.983 & 0.000 \\
\hline
\end{tabular}




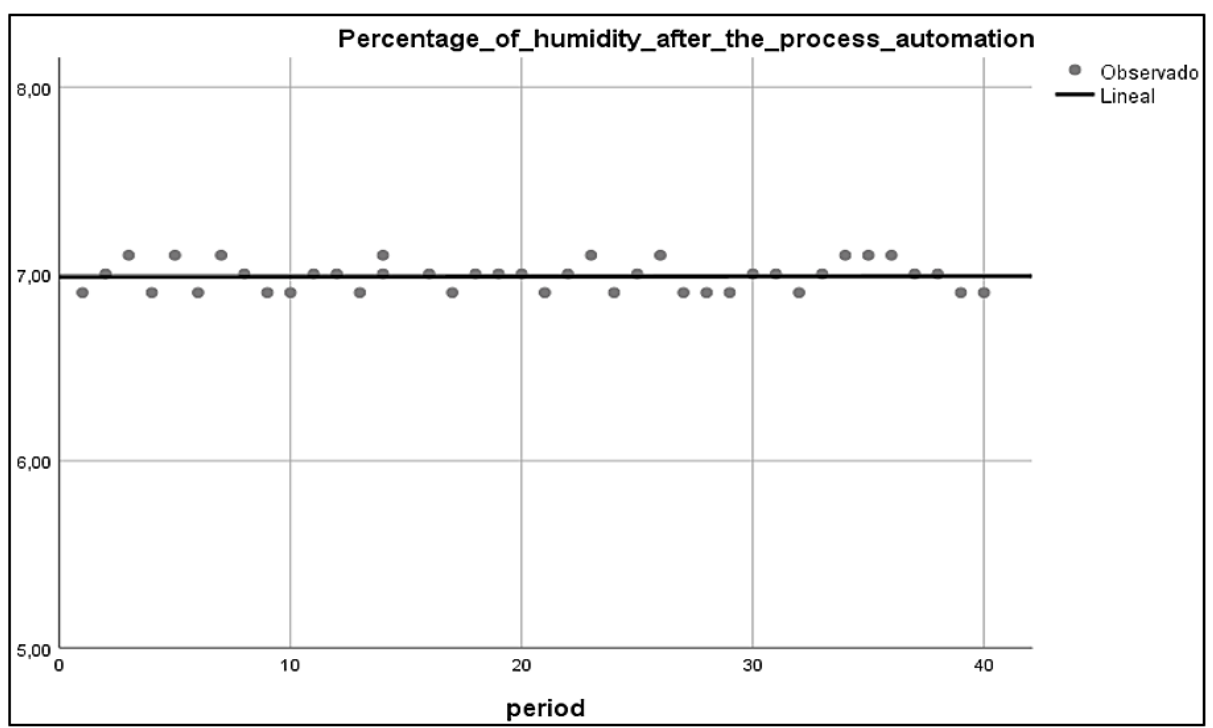

Figure 5. Curvilinear estimation model of the controlled variable

\subsection{Discussions}

In relation to the definitional objectives to be determined as part of the research, the discussions in relation to the results obtained are detailed. In the first place, it was found that under the control strategy proposed and implemented in the sand granulation process, it was possible to improve the percentage of humidity, which consequently will improve the homogeneity in the manufacture of ceramic tiles, this percentage improvement turned out to be $94.78 \%$; In this regard, in the research carried out by [38], in which it specifies that through an automated system it manages to improve the quality of the sand granulation process by $55.75 \%$, in this aspect it is from a point of view that it is a fact that industrial automation improves various aspects in a process, however, what is relevant and outstanding is to what extent the improvement is made, and in this aspect the strategy used is highly significant and contributes much to improving the quality of the manufacturing process of ceramic tiles.

Another aspect that is important to highlight as part of the findings of this research is the degree of approximation of the measured variable with respect to the set point value defined in the process; in this case, the difference is 0.015; this value has to do with the precision of the proposed control system. In this regard, in [39] a precision of 0.020 is achieved. In this regard, in the first case it relies on based control strategies not defined by a PLC (programmable logic controller), but by bilateral PID controllers (proportional, integrator and derivative), whose Tuning may be an aspect that generates that greater variation with respect to the value determined in this investigation. While as indicated in [40] an approximation of 0.018 is achieved, in this case the control strategy was carried out through adaptive digital regulators, whose level of precision is significantly good.

\section{CONCLUSION}

In relation to the results obtained, it is concluded that. Based on the proposed control strategy, that is, controlling the sand flow through frequency variators and by sequential injection of water through valves with nozzles, it was possible to improve the homogeneity percentage by $94.78 \%$, compared to what was had in the manual process; and therefore the homogeneity and quality of the elaboration of ceramic tiles will be improved; However, every industrial process must be monitored, this leads us to recommend that a data acquisition and supervision system should be implemented, since it is not enough to just have a process implemented at the field level and control level, but it must also necessarily be supported by data acquisition and supervision systems so that much necessary and important information can be provided for decisionmaking for the management of the production process. Another aspect to highlight is that a significant precision of around 0.015 was achieved in relation to the desired value or set point defined for the controlled variable, in that sense the control strategy implemented with programmable logic controllers, with which it can be affirmed that it is achieved the purpose of keeping the variable within the pre-established range. From this automated system, it was also possible to improve the precision of each of the elements or inputs that intervene in the dosage, that is, the homogeneity of inputs was achieved, with which it was possible to improve the quality of the ceramic tiles. 


\section{REFERENCES}

[1] Fonfría, A., Díaz, C., and Alvarez, I., "The Role of Technology and Competitiveness Policies: A Technology Gap Approach," Journal of Interdisciplinary Economics, vol. 12, pp. 124-132, 2020, doi: 10.1177/02601079X02001300110.

[2] Awfeeq, N. N., Marie, M. J., and Gaeid, K. S., "Computer control of teaching enhancement by communication networked," Indonesian Journal of Electrical Engineering and Computer Science (IJEECS), vol. 18, no. 2, pp. 736-744, 2020, doi: 10.11591/ijeecs.v18.i2.pp736-744.

[3] Ismail M. et al., "e-PADI: An IoT-based paddy productivity monitoring and advisory system," Indonesian Journal of Electrical Engineering and Computer Science (IJEECS), vol. 14, pp. 852-858, 2019, doi: 10.11591/ijeecs.v14.i2.pp852-858.

[4] Alconcer, P., Calero, M., and Cedeño, N., "Automation of industrial processes," Journal of Business and Entrepreneurial Studies, vol. 12, pp. 124-132, 2020, doi: 10.37956/jbes.v4i2.82.

[5] Chamorro-Atalaya, O. and Arce-Santillan, D., "Fire alert system through text messages, with arduino mega technology and GSM SIM 900 module," Indonesian Journal of Electrical Engineering and Computer Science (IJEECS), vol. 18, no. 3, pp. 1215-1221, 2020, doi: 10.11591/ijeecs.v18.i3.pp1215-1221.

[6] Lozada, M., "Automation of the loss counting of the Production process of tiles in the company Ecuatoriana de Cerámica using a Real time monitoring system," M.S. Thesis, Politécnica Superior School of Chimborazo, Ecuador, 2017.

[7] Chamorro-Atalaya O. et al., "Automatic control of motors through Simocode pro, and its effect on the performance of the process of filling and dispensing of chemical inputs," Indonesian Journal of Electrical Engineering and Computer Science (IJEECS), vol. 23, no. 1, pp. 179-187, 2021, doi: 10.11591/ijeecs.v23.i1.pp179-187.

[8] Arafa, M. I. A. and Said, E.- S. S. A., "A different vision for uninterruptible load using hybrid solar-grid energy," International Journal of Power Electronics and Drive Systems (IJPEDS), vol. 10, no. 1, pp. 381-387, 2019, doi: 10.11591/ijpeds.v10n1.pp381-387.

[9] Spies, J. J. and Kotze, B., "Automated library booktruck for traditional libraries," Indonesian Journal of Electrical Engineering and Computer Science (IJEECS), vol. 15, no. 2, pp. 1095-1101, 2019, doi: 10.11591/ijeecs.v15.i2.pp1095-1101.

[10] Bastidas, G., "Design of a digital image processing system for the detection of surface flaws in the ceramic tiles of the Lima factories," M. Thesis, Technological University of Peru, Lima, 2019.

[11] Abuelhaija, A., Jebrein, A., and Baldawi, T., "Swarm robotics: Design and implementation," International Journal of Electrical and Computer Engineering (IJECE), vol. 10, no. 2, pp. 2173-2181, 2020, doi: 10.11591/ijece.v10i2.pp2173-2181.

[12] Hermann, M., Pentek, T., and Otto, B., "Design principles for Industrie 4.0 scenarios: a literature review," 2016 49th Hawaii International Conference on System Sciences (HICSS), 2016, pp. 415-432, doi: 10.1109/HICSS.2016.488.

[13] Chamorro-Atalaya, O., Goicochea-Vilela, D., Arce-Santillan, D., Diaz-Choque, M., and Diaz-Leyva, T., "Automation of the burner of a pirotubular boiler to improve the efficiency in the generation of steam," Indonesian Journal of Electrical Engineering and Computer Science (IJEECS), vol. 21, no. 1, pp. 101-109, doi: 10.11591/ijeecs. v21.i1.pp101-109.

[14] Narayan, S. and Lakshminarayana, C., "Performance enhancement in active power filter (APF) by FPGA implementation," International Journal of Electrical and Computer Engineering (IJECE), vol. 8, no. 2, pp. 689-698, 2018, doi: 10.11591/ijece.v8i2.pp689-698.

[15] Drath, R. and Horch, A., "Industrie 4.0: Hit or Hype?," IEEE Industrial Electronics Journal, vol. 8, no. 2, pp. 56-58, 2015, doi: 10.1109/MIE.2014.2312079.

[16] Aspar, Z., Shaikh-Husin, N., and Khalil Bin Mohd Hani, M., "Algorithm to convert signal interpreted petri net models to programmable logic controller ladder logic diagram models," Indonesian Journal of Electrical Engineering and Computer Science (IJEECS), vol. 10, no. 3, pp. 905-916, 2018, doi: 10.11591/ijeecs.v10.i3.pp905-916.

[17] Kasim, M. Z. and Anwar N. I., "Industry 4.0 with intelligent manufacturing $5 \mathrm{G}$ mobile robot based on genetic algorithm," Indonesian Journal of Electrical Engineering and Computer Science, vol. 23, no. 3, pp. 1376-1384, 2021, doi: 10.11591/ijeecs.v23.i3.pp1376-1384.

[18] Chamorro-Atalaya, O., Arce-Santillan, D., Diaz-Leyva, T., and Diaz-Choque, M., "Supervision and control by SCADA of an automated fire system," Indonesian Journal of Electrical Engineering and Computer Science (IJEECS), vol. 21, no. 1, pp. 92-100, 2021, doi: 10.11591/ijeecs.v21.i1.pp92-100.

[19] Abbas, H. M. A., Chisab, R. F., and Mnati, M. J., "Monitoring and controlling the speed and direction of a DC motor through FPGA and comparison of FPGA for speed and performance optimization," International Journal of Electrical and Computer Engineering (IJECE), vol. 11, no. 5, pp. 3903-3912, 2021, doi: 10.11591/ijece.v11i5. pp3903-3912.

[20] Ovalle, M., Ocampo, O., and Acevedo, T., "Identification of gaps in industrial automation of companies in the metalworking sector of Caldas," Engineering and Competitiveness Journal, vol. 15, pp. 171-182, 2018.

[21] Luja, M. and Vásquez, V., "Automatic control with fuzzy logic of home-made beer production in maceration and cooking stages," Scientia Agropecuaria, vol. 1, pp. 125-137, 2016, doi: 10.17268/sci.agropecu.2010.02.03.

[22] Cevallos, O., Acosta, R. B., Mora, K. B., and Muñoz, C. E., "Analysis of the levels of automation of industrial processes in a water bottling company in Spanish Análisis de los niveles de automatización de los procesos industriales en empresa envasadora de agua," Journal of Business and Entrepreneurial Studies, vol. 4, no. 2, pp. 24-31, 2020, doi: 10.37956/jbes.v4i2.71. 
[23] Brandl, F., Kagerer, M., and Reinhart, G., "A Hybrid Innovation Management Framework for ManufacturingEnablers for more Agility in Plants," Procedia CIRP Journal, vol. 72, pp. 1154-1159, 2018, doi: 10.1016/j.procir.2018.04.022.

[24] Pérez, E., "Proposal for Automation in a finished product warehouse in a product manufacturing industry in Costa Rica," Journal InterSedes, vol. 16, no. 34, pp. 40-60, 2016.

[25] Quezasa-Quezada, J., Bautista-López, J., Flores-Garcias, E., and Quezada-Aguilar, V., "Design and implementation of a control and monitoring system based on HMI-PLC for a drinking water well," Engineering Research and Technology Magazine, vol. 15, pp. 41-50, 2016.

[26] Mera, L. E., Ibarra, M. Y., Menéndez, B. A. and Menéndez, B. J., "Analysis of the automation levels of the company produsiembal Cia. Ltda in Spanish Análisis de los niveles de automatización de la empresa produsiembal Cia. Ltda," Journal of Business and Entrepreneurial Studies, vol. 4, no. 2, pp. 107-113, 2020, doi: 10.37956/jbes.v4i2.80.

[27] Baque, L., Aguirre, C., Barreto, N., and Barros, K., "Automation and air conditioning levels in the corn sheller manufacturing process in Spanish Niveles de automatización y climatización en el proceso de fabricación de la desgranadora de maíz," Journal of Business and Entrepreneurial Studies, vol. 4, no. 2, pp. 45-60, 2020, doi: $10.37956 /$ jbes.v4i2.73.

[28] Mejía-Neira, A. et al., "The Influence of Software Engineering on Industrial Automation Processes," Technology Information Journal, vol. 30, pp. 221-230, 2019.

[29] Mendoza, M., "Automation of the granulating process, for the improvement of the homogeneity of the wet powder, in the production of mayolicas, in the factory ceramic San Lorenzo," MS. Thesis, Alas Peruanas University, Peru, 2019.

[30] Baque, L., Vasquez, C., Moserratte, D., and Quiñonez, K., "Analysis of the levels of automation of cocoa production processes in Spanish Análisis de los niveles de automatización de los procesos de producción de cacao," Journal of Business and Entrepreneurial Studies, vol. 4, no. 2, pp. 8-23, 2020, doi: 10.37956/jbes.v4i2.70.

[31] Alconcer, P., Miranda, B., and Alava, K., "Analysis of the automation levels of the industrial processes of the company "Balsariver Cía. Ltda" in Spanish Análisis de los niveles de automatización de los procesos industriales de la empresa "Balsariver Cía. Ltda.," Journal of Business and Entrepreneurial Studies, vol. 4, no. 2, pp. 259-265, 2020, doi: 10.37956/jbes.v4i2.101.

[32] Alarcon, F., Alemany, M., Lario, F., and Oltra, R., "The lack of homogeneity of the product (FHP) in ceramic companies and its impact on the reallocation of inventory," Spanish Society of Ceramics and Glass Journal, vol. 50, pp. 49-58, 2016, doi: 10.3989/cyv.072011.

[33] Baek, K., Heon, D., and Jun, H., "Automatic segmentation of ceramic materials with relaxed possibilistic c-means clustering for defect detection," Indonesian Journal of Electrical Engineering and Computer Science (IJEECS), vol. 19, pp. 1505-1511, 2020, doi: 10.11591/ijeecs.v19.i3.pp1505-1511.

[34] Upendra, R., Umesh, M., Ravi, R., and Basavaprasad, B., "Technology in Indian agriculture - a review," Indonesian Journal of Electrical Engineering and Computer Science (IJEECS), vol. 20, no. 2, pp. 1070-1077, 2020, doi: 10.11591/ijeecs.v20.i2.pp1070-1077.

[35] Hurtado, H., Velasquez C., and Mártinez, J.,"Corporate social responsibility in the ceramic sector, The management of CSR as a means of maximizing the productivity and profitability in certified companies with ISO 9001 and Basc. Analysis of a local company during the period 2015-2016 Case: Cerámica Lima S.A. - CELIMA,” MS. Thesis, Universidad Peruana de Ciencias Aplicadas, Peru, 2021.

[36] Mallol, J., "Control and automation in the ceramic industry, Evolution and Prospects," Journal Qualicer, vol. 13, pp. 47-72, 2016.

[37] Fareeza, F. Rambabu, C. Krishnaveni S., and Kabiso, A. C., "Automation of DMPS manufacturing by Using LabView and PLC," International Journal of Electrical and Computer Engineering (IJECE), vol. 8, no. 6, pp. 5484-5494, 2018, doi: 10.11591/ijece.v8i6.pp5484-5494.

[38] Mohammed, N., Danapalasingam, K. A., and Majed, A., "Design, control and monitoring of an offline mobile battery energy storage system for a typical malaysian household load using PLC," International Journal of Power Electronics and Drive Systems (IJPEDS), vol. 9, no. 1, pp. 180-188, 2018, doi: 10.11591/ijpeds.v9.i1.pp180-188.

[39] Cera-Martínez, D., Ortiz-Sandoval, J., and Gualdrón-Guerrero, O., "Tuning of a temperature controller through a programmable automatism," Revista de Investigación, Desarrollo e Innovación, vol. 9, no. 1, pp. 177-186, 2018, doi: 10.19053/20278306.v9.n1.2018.8513.

[40] Duque, A., Lopéz, J., and Felipe, A., "Auto-tuning of a PID controller implemented in a PLC using swarm intelligence,” Prospective Journal, vol. 15, pp. 35-41, 2017, doi: 10.15665/rp.v15i1.679. 